\title{
Diversity of conversion strategies for organic vineyards
}

\author{
Anne Merot ${ }^{1}$ (I) $\cdot$ Adeline Alonso Ugaglia $^{2} \cdot$ Jean-Marc Barbier ${ }^{3} \cdot$ Bernard Del'homme $^{4}$
}

Accepted: 21 January 2019 / Published online: 4 March 2019

(C) INRA and Springer-Verlag France SAS, part of Springer Nature 2019

\begin{abstract}
An increasing number of vineyards are converting to organic farming due to concerns about the environmental impacts of agriculture. How difficult this shift is depends on farms' biophysical and economic situations as well as on their specific dynamics. Methods to analyze, assess, and support transition strategies are needed. In this context, the hypothesis can be made that the efficiency-substitution-redesign approach, which is used for describing the level, intensity, and speed of changes made by vineyards, could be used to classify transition strategies. On-farm interviews and surveys were conducted at vineyards in conversion to organic farming in two French winegrowing regions: Languedoc and Bordeaux. The agronomic changes made to various grape production technical operations during the conversion period were described and assessed by using the efficiency-substitution-redesign approach. Potential economic consequences of conversion were measured by looking at farms' accounting records. Considering the high number of variables taken into account in the detailed analysis of each operation for the conversion to organic farming, the efficiency-substitution-redesign approach was successfully used to classify transition strategies according to the type of changes made. The results showed that change intensity varied between farms with no clear correlation between the type of changes and economic consequences. Farm trajectories were then correlated to the speed and intensity of changes with quantitative transition indicators. Here, a quantitative application of the efficiency-substitution-redesign approach was used for the first time to assess and classify organic farming conversion strategies according to a scale of change intensity and speed of changes. These results are essential to enhance understanding of what happens during conversion to organic farming and to better support winegrowers' trajectories.
\end{abstract}

Keywords Transition $\cdot$ Organic farming $\cdot$ Efficiency $\cdot$ Substitution $\cdot$ Redesign $\cdot$ Adaptive cycle $\cdot$ Resilience

\section{Introduction}

An increasing number of farms in Europe are converting to organic farming due to concerns about the environmental impacts of agriculture (Bellon and Penvern 2014). Organic farming has developed rapidly in France over the past decade, and viticulture is one of the key farming sectors making the shift to organic (Fig. 1), both in terms of hectares and number of farms. In 2016, the surface area of organic vineyards was

Anne Merot

anne.merot@inra.fr

1 UMR System, INRA, 34060 Montpellier, France

2 Bordeaux Sciences Agro, UMR SAVE, ISVV, 33175 Gradignan, France

3 UMR Innovation, INRA, 34060 Montpellier, France

4 UR ETBX, Bordeaux Sciences Agro, 33175 Gradignan, France
$9 \%$, or 70,000 ha, of the country's total vineyard area (Agence bio 2016).

For vineyards, converting to organic farming requires replacing synthetic chemicals with more environmentally friendly solutions such as sexual confusion and preventive operations such as mechanical soil management instead of chemical management (Fig. 1). Organic conversion is a considerable undertaking in terms of limiting synthetic pesticide use, and while there are no studies pertaining specifically to vineyard systems, research has shown an impact on agronomic and economic performances for other crops. A significant drop in per-hectare yields in organic farming compared to conventional agriculture has been observed (de Ponti et al. 2012; Seufert et al. 2012), but related economic losses have not been demonstrated. For grapevines, the risk of yield losses seems to be important during organic conversion because grape yields are highly sensitive to pests and diseases (Fermaud et al. 2016). Organic farming labor requirements and total costs per hectare can be two or three times greater 


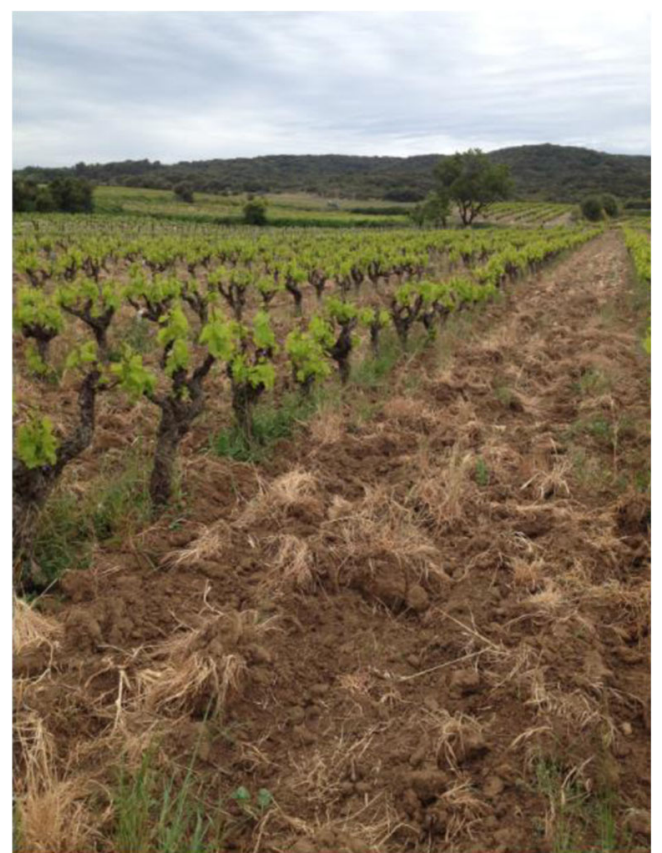

Fig. 1 Vineyard in conversion to organic farming in May in the Tavel region, southern France. The photo was taken just after mechanical weeding in the inter-row. Photo by Anne Merot

than those in conventional agriculture (Aubert and Enjolras 2017) depending on cropping choices (e.g., mechanization) and pre-conversion synthetic chemical dependency. A study carried out on a large set of cropping systems using the Farm Accountancy Data Network (European Commission 2018) database showed that organic farming is characterized by large-scale investments in special equipment, higher labor costs, and greater sensitivity to climate risks due to pesticide limitations (Butault et al. 2010). Simultaneously analyzing changes in costs and the intensity of the technical changes presents a major challenge.

The organic conversion process differs from one farm to another. The shift may occur very quickly or it may be a continuous process of adaptation (Lamine and Bellon 2009). Some agricultural advisers worry about the survival of farms that convert without being sufficiently prepared, especially since the knowledge needed to ensure such a major change is not easily accessible. Change strategies need to be classified and the weakest situations requiring the most effort to achieve organic conversion must be identified.

Some studies, although not specifically focused on viticulture, have examined the various aspects of the organic changeover process (Lamine and Bellon 2009). This research often considered conversion as a delimited step with "before conversion" and "after conversion" states. These studies described the conditions of the conversion, linking them with the decision to convert or gave evidence of agronomic and economic performances following conversion (Seufert et al. 2012). Very few of them offered a year-by-year analysis or combined both technical and socioeconomic viewpoints (Sautereau and Petitgenet 2014). Methods to analyze, assess, or classify transition strategies are needed.

Le Pichon et al. (2013) proposed an approach to classify transition based on three strategies differing by the time scale of action (short term, medium term, and long term) to assess the significance of changes. Geels and Schot (2007) also proposed a typology of transition pathways that was mostly descriptive and qualitative, and which was also more applicable to the development stages of niche innovations. At the cropping system level, Hill and MacRae (1995) suggested describing the transition from conventional to more sustainable farming according to three stages: "efficiency, substitution, and redesign or the 3Rs: reduce, replace and redesign." Efficiency reduces both resource consumption and environmental impacts. In the substitution stage, resources or inputs are replaced by more environmentally friendly options. During the redesign stage, the system is largely rethought and restructured. This framework has been used to classify innovations (Wezel et al. 2014) and has also been used to investigate the degree of progress towards sustainable development and ecological intensification (Patriquin 1999). The main applications of the efficiencysubstitution-redesign framework have often been focused on pest management (Estevez et al. 2000). The applications have been performed on the farm system (Lamine 2011) or the agrifood system (Gliessman 2007; see also Gliessman and Rosemeyer 2010). Whatever the scale of application, studies using the efficiency-substitutionredesign framework were mostly theoretical or qualitative, and more quantitative approaches are lacking.

In this article, the general efficiency-substitution-redesign concept proposed by Hill and MacRae (1995) is used to classify transition strategies in a simple way. This approach was tested on vineyards converting to organic farming to characterize the wide range of transition strategies and assess the intensity of change of conversion within the farm trajectory. The focus is on grape production activity at a farm scale, and both technical and economic viewpoints are given to show the importance of and need for a multidisciplinary and integrated approach to this type of evaluation.

\section{Materials and methods}

\subsection{Case study}

\subsubsection{Scope of the study—official conversion}

The efficiency-substitution-redesign framework was applied to vineyards during their official conversion to organic farming. For vineyards, the conversion process takes 3 years. This means that some farms could have begun the transition 
process towards organic farming long before the official conversion or not. However, the official conversion is the reference in terms of technical management, aid, cases of advice from government agencies, and the economic valuation of reducing chemical product use. During this 3-year period, the vineyard is not considered organic, so its products cannot be sold at a higher price than conventionally grown grapes.

As is usually done in accounting management (Bouquin 2004), a farm can be broken down into different activities representing each production process (for grape production, this includes harvest, wine processing, aging, packaging, and sales). Here, the vineyard system is defined at a farm scale for vineyards in conversion to organic farming as a grape production activity comprised of a biophysical subsystem interacting with a technical subsystem (Le Gal et al. 2010). The biophysical subsystem is a crop-soil-pest system that is impacted by farmers' technical operations. The grape production activity is associated with grape production costs.

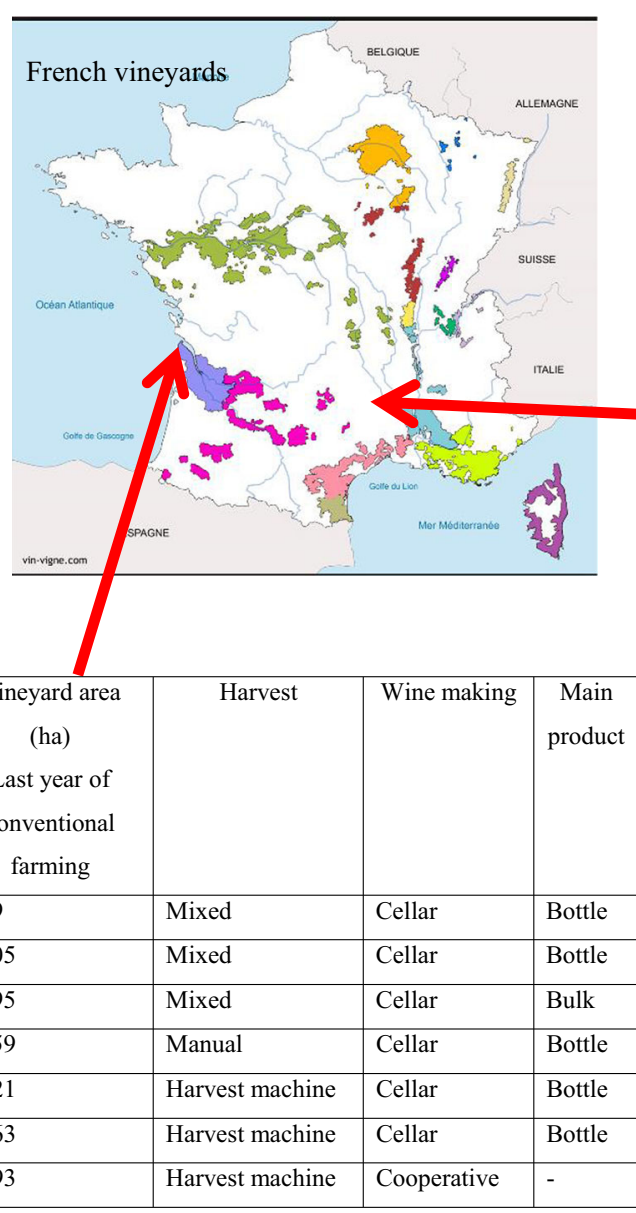

\begin{tabular}{|c|c|c|c|c|}
\hline $\begin{array}{l}\text { Farm } \\
\text { number }\end{array}$ & $\begin{array}{l}\text { Vineyard area } \\
\text { (ha) } \\
\text { Last year of } \\
\text { conventional } \\
\text { farming }\end{array}$ & Harvest & Wine making & $\begin{array}{l}\text { Main } \\
\text { product }\end{array}$ \\
\hline B-1 & 4.19 & Mixed & Cellar & Bottle \\
\hline B-2 & 16.05 & Mixed & Cellar & Bottle \\
\hline B-3 & 13.95 & Mixed & Cellar & Bulk \\
\hline B-4 & 24.59 & Manual & Cellar & Bottle \\
\hline B-5 & 70.21 & Harvest machine & Cellar & Bottle \\
\hline B-6 & 23.63 & Harvest machine & Cellar & Bottle \\
\hline B-7 & 15.93 & Harvest machine & Cooperative & - \\
\hline
\end{tabular}

Fig. 2 Presentation of the farms studied. Two French winegrowing regions were studied: Bordeaux on the left side and Languedoc on the right side of the figure. Seven and 20 farms were respectively studied in

\subsubsection{Sampling}

The sample comprises vineyards in southwestern France (Bordeaux region) and in southeastern France (Languedoc region), the country's two major winegrowing areas. Sampling differed slightly for the two approaches (technical and economic) depending on winegrowers' willingness to provide access to their accounting information. The sample for the technical analysis of the grape production system includes 16 vineyards located in Languedoc (Fig. 2). The economic system analysis sample includes 13 vineyards in the Bordeaux and Languedoc regions. The observed conversions towards organic farming were undertaken between 2009 and 2013. The study includes some vineyards in common for both analyses (in gray in Fig. 2). A range of grape production conditions is identified according to farm size (vineyard area for production), harvest type (manual, mechanized or both), and average yields and business model (individual winery or cooperative winery), as well as the main product type (bottle,

\begin{tabular}{|l|l|l|l|l|}
\hline $\begin{array}{c}\text { Farm } \\
\text { number }\end{array}$ & $\begin{array}{c}\text { Vineyard area } \\
\text { (ha) } \\
\text { Last year of } \\
\text { conventional } \\
\text { farming }\end{array}$ & \multicolumn{1}{|c|}{ Harvest } & Wine making & $\begin{array}{c}\text { Main } \\
\text { product }\end{array}$ \\
\hline ME-1 & 7.85 & Manual & Cellar & Bottle \\
\hline ME-2 & 13.00 & Mixed & Cellar & Bulk \\
\hline ME-3 & 52.14 & Mixed & Cellar & Mixed \\
\hline ME-4 & 13.76 & Manual & Cellar & Bottle \\
\hline ME-5 & 36.16 & Harvest machine & Cooperative & - \\
\hline ME-6 & 52.00 & Harvest machine & Cellar & Bulk \\
\hline ME-7 & 33.00 & Harvest machine & Cooperative & - \\
\hline ME-8 & 8.25 & Manual & Cellar & Bottle \\
\hline ME-9 & 16.03 & Harvest machine & Cooperative & - \\
\hline ME-10 & 28.57 & Harvest machine & Cellar & Mixed \\
\hline ME-11 & 18.50 & Manual & Cellar & Bottle \\
\hline ME-12 & 19.00 & Harvest machine & Cooperative & Mixed \\
\hline ME-13 & 10.70 & Manual & Cooperative & Mixed \\
\hline ME-14 & 5 & Harvest machine & Cooperative & Mixed \\
\hline ME-15 & 90 & Harvest machine & Cellar & Mixed \\
\hline ME-16 & 35.00 & Harvest machine & Cooperative & Mixed \\
\hline ME-17 & 9.30 & 22 & Cellar & Bottle \\
\hline ME-18 & 21.90 & Cellar & Mixed \\
\hline ME-19 & 20.66 & Cellar & Mixed \\
\hline ME-20 & \begin{tabular}{l} 
Manual \\
\hline
\end{tabular} & Cooperative & Mixed \\
\hline
\end{tabular}

Bordeaux region and Languedoc region. They are classified depending on the vineyard area, harvesting method, and the choice of on-farm winemaking and the main products 
bulk, or both) (Fig. 2). Farm types varied substantially across the two regions studied. Four vineyards were studied in terms of the cropping system and economic system.

\subsubsection{Data collection}

Surveys were used to collect information for the technical analysis of the grape production system and for the economic system analysis. General characteristics for all of the case study farms were collected: city, legal structure, vineyard area, target yield, date of administrative conversion (mostly recent in the sample to improve data accessibility), and level of conversion (partial or total). For the technical approach of the vineyard system, semi-directive interviews focused on changes in technical operations. They were performed from the first year of the conversion, followed by the second year, the third year, and the first year organic certification was obtained. For each technical operation, information on implementation, equipment, and product was collected on conventional farming and each year of the conversion to identify and characterize changes from 1 year to the next. For the economic approach, accounting records (balance sheets, revenue accounts, and detailed expense accounts) were collected for the 3-year conversion period as well as the year before and the year after (e.g., 5 years in all) as well as extra data to allocate costs for different activities and products.

\subsection{Efficiency-substitution-redesign framework adjusted for conversion strategy analysis}

Hill and MacRae (1995) put forward a framework of "organized potential transition strategies" to analyze and implement a transition focused on resource preservation. It is based on three notions: efficiency, substitution, and redesign. Efficiency is associated with low-input agriculture, substitution with more environmentally friendly inputs and eco-agriculture, and redesign with prevention and management measures. For vineyards, the efficiencysubstitution-redesign framework is defined as follows: "efficiency increase refers to technical operations that reduce input consumption (e.g., water, pesticides, and fertilizers) while maintaining crop productivity"; "substitution practices refer to the substitution of an input or a practice by another (e.g., replacing chemical pesticides by natural pesticides"); and redesign "refers to the change of the whole cropping or even farming system" (Wezel et al. 2014). It seems essential to broaden the concept (particularly as it applies to perennial cropping systems) in light of the variety of changes observed and because a process (conversion) is assessed over time in an integrated way. According to Hill and MacRae (1995), redesign is achieved when the causes of problems are recognized and limited. The redesign of a technical operation means that adopting the practice in question leads to rethinking part or all of the technical system. For perennial crop systems such as vineyards, changing varieties, crop rotations, or the planting density (distance between two rows, density, rootstock, etc.) is not possible. Redesign is therefore often less ambitious than what could be implemented for annual crops and limited to changes in the annual crop management sequence. For example, redesign was observed when winegrowers decided to manage intercropping activities, from seeding to destruction. For this research, efficiencysubstitution-redesign was used to qualify changes implemented for grape production activity. Efficiency, substitution, and redesign were ranked according to a scale of intensity (Hill and MacRae 1995). One consequence is that the initial point before conversion must be integrated because conventional vineyard systems vary greatly. Adapting the efficiency-substitution-redesign framework to organic farming conversion requires the inclusion of another situation: the absence of any identified change, which is indicated by the symbol $\varnothing$.

\subsection{Applying the efficiency-substitution-redesign framework to perennial crop systems during organic conversion for technical and economic aspects}

\subsubsection{Technical analysis of the grape production system}

Each technical operation was first studied separately and observations were then aggregated to avoid the risk of making an empirical assessment of the conversion with the efficiency-substitution-redesign framework. The various technical operations necessary for grape production during a growing season that were impacted by the organic conversion process were analyzed using the efficiencysubstitution-redesign framework adapted for conversion. Eleven operations were considered: phytosanitary strategy against (1) Plasmopara viticola (Berk \& Curt.) and Erysiphe necator, (2) Scaphoideus titanus and Eupoecilia ambiguella (Hübner) and (3) Lobesia botrana (Denis and Schiffermüller); (4) fertilization; (5) weeding in the row and (6) in the inter-row; (7) winter pruning; (8) bud pruning; (9) fall tillage; (10) trimming; and (11) harvest. The next step consisted in using the efficiency-substitutionredesign framework on the various changes to technical operations. For each technical operation, three periods were defined during which changes could occur: from the year before conversion to the first year of conversion (CONV to $\mathrm{C} 1$ ), from the first year of conversion to the second year of conversion ( $\mathrm{C} 1$ to $\mathrm{C} 2$ ), and from the second year of conversion to the third year of conversion ( $\mathrm{C} 2$ to C3).

The efficiency-substitution-redesign framework was applied for these three periods of change and for each technical 
operation. For example, one farmer usually performed chemical bud pruning before conversion in all plots (initial pointlevel 1). He then switched to mechanical bud pruning between CONV to $\mathrm{C} 1$ without the intention to reorganize labor or change his intervention schedule. However, because he was not satisfied by the efficiency of bud pruning, from $\mathrm{C} 1$ to $\mathrm{C} 2$, he decided to prune buds earlier than the two previous years. He was satisfied with the result and did not make any additional changes from $\mathrm{C} 2$ to $\mathrm{C} 3$. The application of the efficiency-substitution-redesign framework resulted in $\mathrm{S}$ from $\mathrm{CONV}$ to $\mathrm{C} 1$, in $\mathrm{E}$ from $\mathrm{C} 1$ to $\mathrm{C} 2$, and in ø from $\mathrm{C} 2$ to $\mathrm{C} 3$. The trajectory of change is $\mathrm{S} / \mathrm{E} / \varnothing$ for the technical operation.

The application of the efficiency-substitution-redesign framework was then used to build the table of changes for the whole set of technical operations and the three periods observed. A final efficiency-substitution-redesign score was proposed to rank conversion strategies (Formula 1). For each farm, the number of Es was counted, followed by the number of Ss, the number of Rs, and, finally, the total efficiencysubstitution-redesign score (Formula 1) during the conversion, taking into consideration all of the technical operations and the three periods of observation. When the number of Rs was greater than four, the changes were significant and the final efficiency-substitution-redesign score was automatically $\mathrm{R}$. The number of four was chosen because it accounted for nearly half of the technical sequence. During the interviews, it was noted that from four Rs, the repercussions on the whole farming system organization were considerable. For the other cases, the final efficiency-substitution-redesign score corresponded to the situation that obtained the higher scores (Formula 1). The number of Rs was related to the intensity of change during conversion (Formula 2). An indicator for speed of conversion was also calculated. It was given by the addition of the numbers of Es, Ss, and Rs corresponding to the number of changes divided by the duration of the conversion (Formula 3).

Final efficiency-substitution-redesign score

(Formula1)

$$
\begin{gathered}
=\left\{\mathrm{R} \text { if }\left(\left(\left(\Sigma_{\mathrm{ij}} \mathrm{R}>\Sigma_{\mathrm{ij}} \mathrm{S}\right) \text { and }\left(\Sigma_{\mathrm{ij}} \mathrm{R}>\Sigma_{\mathrm{ij}} \mathrm{E}\right)\right) \text { or if }\left(\Sigma_{\mathrm{ij}} \mathrm{R}>=\mathrm{s}\right)\right)\right. \\
; \mathrm{S} \text { if }\left(\left(\Sigma_{\mathrm{ij}} \mathrm{S}>\Sigma_{\mathrm{ij}} \mathrm{R}\right) \text { and }\left(\Sigma_{\mathrm{ij}} \mathrm{S}>\Sigma_{\mathrm{ij}} \mathrm{E}\right)\right) \\
\left.\mathrm{E} \text { if }\left(\left(\Sigma_{\mathrm{ij}} \mathrm{E}>\Sigma_{\mathrm{ij}} \mathrm{S}\right) \text { and }\left(\Sigma_{\mathrm{ij}} \mathrm{E}>\Sigma_{\mathrm{ij}} \mathrm{R}\right)\right)\right\}
\end{gathered}
$$

with $\mathrm{i}=$ the periods of change and $\mathrm{j}=$ the technical operations; with $s=4$ because if $4 / 11$ (or more than 4/11) technical operations are redesigned, the whole crop management sequence is substantially altered.

$$
\text { Intensity of change }=\Sigma_{\mathrm{ij}} \mathrm{R}
$$

with $\mathrm{i}=$ the periods of change and $\mathrm{j}=$ the technical operations.

Speed of change $=\left(\Sigma_{\mathrm{ij}} \mathrm{E}+\Sigma_{\mathrm{ij}} \mathrm{S}+\Sigma_{\mathrm{ij}} \mathrm{R}\right) / 3 \quad$ (Formula3) with $\mathrm{i}=$ the periods of change, $\mathrm{j}=$ the technical operations and $3=$ the number of years of official conversion.

\subsubsection{Economic analysis of the grape production system}

Changes made when converting to organic may affect a farm's economic results with immediate or delayed effects and at different intensities. The economic analysis is based on the vineyard system rather than focusing on the differentiated technical operations or the economic performance of the whole vineyard. Grape production costs were analyzed as they are more relevant for an analysis combined with the technical evaluation of grape growing using the efficiency-substitutionredesign method. The choice was made to study these costs rather than economic results or statement balances because the latter are impacted by a farm's other activities (wine processing, aging, packaging, and sales) and management decisions (e.g., investments). Focusing on grape production costs provides a clear, easily understandable indicator that is easier to access. The impact of a technical change is then analyzed from an economic standpoint to characterize the intensity of change according to variations in grape production costs. The hypothesis behind this is that the more positive and significant the variation in grape production costs, the more the change must be anticipated, addressed, and managed by the winegrower as a consequence of the technical changes resulting from organic conversion. Indicators relative to vineyard grape production cost changes were also calculated following the activity-based costing method generally used in cost analyses and already applied to vineyards (Alonso Ugaglia and Del'homme 2012; Bouquin 2004; Pailler 2004). This accounting method, which identifies and assigns costs to overhead activities and then assigns those costs to products, can be used to calculate all costs (both direct and indirect) and broken down according to resource consumption by activity using allocation bases. The grape production activity was divided into two sub-activities (Formula 4)-grape growing and harvest - to have specific information on the cost of the harvest, taking into consideration that a change from mechanical to manual harvesting (or vice versa) would have a major impact on grape production costs. Two different units, the production area (hectares, or ha) and the volume of production (hectoliters, or hl), were considered to take into account the potential impact on yields.

\section{Cost of grape production}

$=$ Cost of grape growing

+ Cost of grape harvesting

(Formula4) 
The cost of grape production during the first year of certified organic farming (OF) and the last year before the beginning of the conversion (CONV) were compared, first using the absolute value and then using the percentage it represents.

Variation in grape production costs

$=$ Cost of OF grape production-Cost of CONV grape production

(Formula5)

A weighted overall variation in costs for the cropping system (see Formula 5) was then calculated. Finally, the R 3.5.0 software was used to perform linear regression and an analysis of covariance.

\section{Results and discussion}

\subsection{Efficiency-substitution-redesign in ranking technical grape production conversion strategies}

\subsubsection{Type of changes}

Various types of changes were observed during the study. Certain changes were made to improve efficiency using the same inputs for an equivalent performance. The inputs in this study were organic pesticides, organic fertilizers, labor, use of agricultural machinery, and biofuel consumption. Efficiency can be achieved by reducing the doses of the first applications of copper and sulfur. The more obvious and expected changes during conversion were substitutions. The analysis showed that sulfur- or copper-based products were mostly used instead of synthetic chemicals. Insecticides were replaced by sexual confusion solutions. New equipment (mainly mechanical weeders) was also used to replace chemicals or older equipment. When this was the case, there were two types of situations: substitution or redesign.

With regard to substitution, equipment was managed using the same decision rules as with chemicals. For example, chemical bud pruning was often replaced by mechanical bud pruning initially performed at the same time of the year. With regard to redesign, a change was observed in the implementation conditions (decision rules, frequency, labor) made by the farmer with broader implications than just the technical operation assessed. With the example of bud pruning, some farmers decided to bring the date of intervention forward because the machines could not perform efficient bud pruning on overly lignified branches. The consequences were that two interventions were often necessary instead of only one chemical-based intervention; as a result, this more time-consuming intervention led to a change across the technical management sequence. When chemicals were replaced with manual interventions, the time needed to perform technical operations always increased, requiring work planning to be reorganized.

Redesign situations were not often observed, except for mechanical weeding in the row and inter-row or fertilization (which is closely linked to soil management choices). For example, in one vineyard, the winegrower decided to implement an intercrop in the row to (1) aerate the soil with root colonization; (2) limit soil compaction; and (3) provide fertilizer or organic matter depending on plot requirements. Given this set of objectives and to avoid creating water and nitrogen competition with the vines, he had to choose a combination of suitable intercrops.

\subsubsection{Efficiency-substitution-redesign in ranking technical operations}

Across the whole set of farms interviewed, the changes made to the technical operations were analyzed. Changes varied widely from one technical operation to another. First of all, harvest and tillage were not impacted by conversion. These operations were not considered in the analysis. Only nine operations were considered in the analysis. The other operations were split into four groups.

The first group includes operations that remain unchanged by the conversion process (no change for 11/16 farms) such as pruning and topping. When changes were observed, they were made to improve efficiency (E).

- The second group includes operations that are clearly at the origin of a redesign $(\mathrm{R})$ of the technical system compared to conventional agriculture, such as weeding in the row ( $\mathrm{R}$ for $14 / 16$ farms). They are directly impacted by the elimination of an input (e.g., herbicides) imposed by organic farming standards.

- The third group includes operations that are almost systematically changed but with a wide range of changes between farms (either $\mathrm{E}$ or $\mathrm{S}$ or at the origin of an $\mathrm{R}$ ) compared to conventional (for 13/16 farms). They are directly impacted by the substitution of inputs imposed by organic farming standards, such as fertilization (E, S, or $\mathrm{R}$ for $13 / 16$ farms) and phytosanitary treatments against downy or powdery mildew ( $\mathrm{R}$ for $6 / 16$ farms and changes observed for 15/16 farms).

The fourth group includes operations that are not systematically changed compared to conventional agriculture (changes only for 10/16 farms) and when changed remain low in intensity ( $\mathrm{S}$ or $\mathrm{E}$ ), such as weeding in the inter-row and vegetative control (bud pruning). They are directly impacted by the conversion towards organic farming because of the limitation of inputs but are often changed before conversion. 
Table 1 Application of the efficiency-substitution-redesign approach for the technical analysis. The table summarizes the number of $\mathrm{E}, \mathrm{S}$, and R over the 3 years of the conversion, then the intensity of changes and the number of changes

\begin{tabular}{lllllll}
\hline $\begin{array}{l}\text { Number of } \\
\text { farms }\end{array}$ & $\begin{array}{l}\text { Number } \\
\text { of R }\end{array}$ & $\begin{array}{l}\text { Number } \\
\text { of S }\end{array}$ & $\begin{array}{l}\text { Number } \\
\text { of E }\end{array}$ & $\begin{array}{l}\text { Absence of change } \\
\text { (number) }\end{array}$ & $\begin{array}{l}\text { Intensity of } \\
\text { changes }\end{array}$ & $\begin{array}{l}\text { Number of } \\
\text { changes }\end{array}$ \\
\hline ME-4 & 0 & 2 & 0 & 25 & $\mathrm{~S}$ & 2 \\
ME-17 & 0 & 3 & 0 & 24 & $\mathrm{~S}$ & 3 \\
ME-18 & 2 & 5 & 1 & 19 & $\mathrm{~S}$ & 8 \\
ME-19 & 1 & 3 & 0 & 23 & $\mathrm{~S}$ & 4 \\
ME-5 & 1 & 5 & 3 & 18 & $\mathrm{~S}$ & 9 \\
ME-15 & 2 & 4 & 2 & 19 & $\mathrm{~S}$ & 8 \\
ME-14 & 2 & 2 & 4 & 19 & $\mathrm{E}$ & 8 \\
ME-16 & 2 & 4 & 8 & 13 & $\mathrm{E}$ & 14 \\
ME-11 & 0 & 1 & 3 & 23 & $\mathrm{E}$ & 4 \\
ME-7 & 4 & 3 & 7 & 13 & $\mathrm{R}$ & 6 \\
ME-1 & 3 & 1 & 2 & 21 & $\mathrm{R}$ & 6 \\
ME-10 & 6 & 2 & 1 & 18 & $\mathrm{R}$ & 8 \\
ME-2 & 4 & 0 & 13 & 10 & $\mathrm{R}$ \\
ME-20 & 3 & 4 & 1 & 19 & $\mathrm{R}$ & 14 \\
ME-12 & 5 & 4 & 7 & 11 & $\mathrm{R}$ & 16 \\
ME-13 & 4 & 3 & 4 & 16 & $\mathrm{R}$ \\
\hline
\end{tabular}

\subsubsection{Final efficiency-substitution-redesign scores on grape production technical conversion strategies}

The final efficiency-substitution-redesign score (Table 1) was used to rank the technical conversion strategies followed by farms surveyed according to E, S, or R. Each farm made changes to the technical operations during conversion. A wide range of differences in the farm conversion profiles was noted. Some farms implemented a combination of $\mathrm{E}, \mathrm{S}$, and $\mathrm{R}$ changes in varying proportions (e.g., farms ME7 and ME16). Some made only one type of change (e.g., ME4 and ME17 substitutions only) while others made both R and $\mathrm{E}$ changes (e.g., ME2) or E and $\mathrm{S}$ (e.g., ME11). However, except for ME16, each technical conversion strategy could be clearly positioned as E, S, or $\mathrm{R}$ (Table 1). Accordingly, 3/16 farms carried out the conversion by improving input efficiency (E). For 6/16 farms, the conversion can be viewed as a set of substitutions (S). For $7 / 16$ farms, the organic conversion is more of a systemic and comprehensive process (R). The calculation of the intensity of change indicator for ME2, ME7, ME10, ME12, and ME13 was especially unambiguous. For these

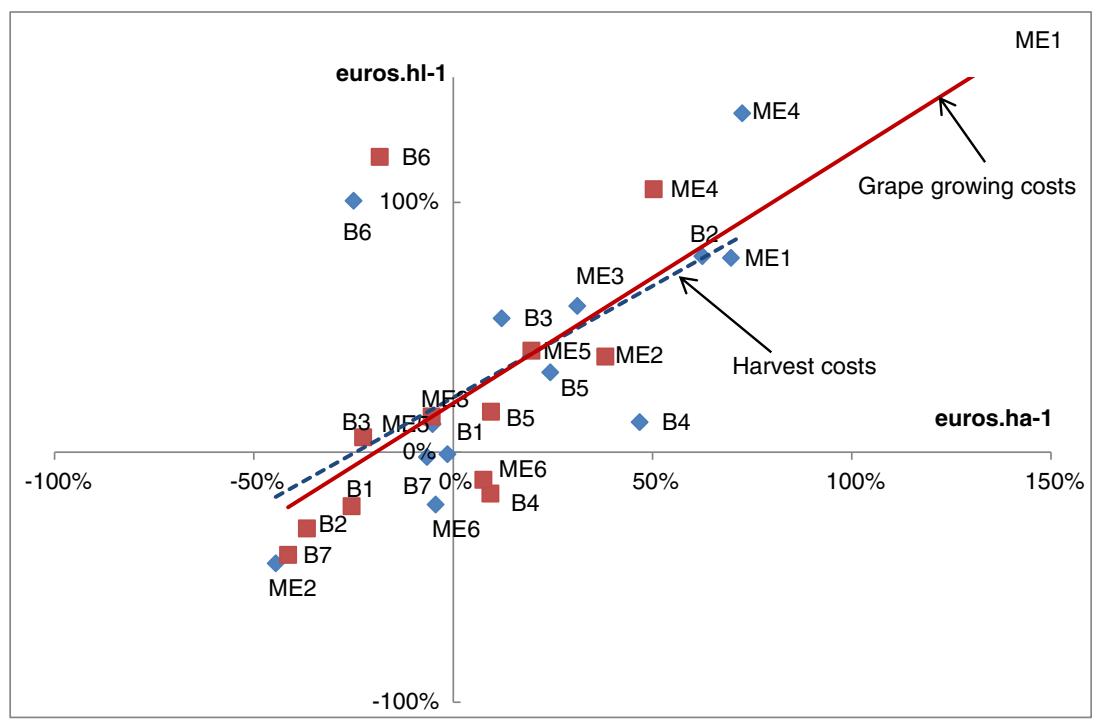

Fig. 3 Variation in costs (\%) for grape growing (square) and harvest (diamond) when costs are calculated relative to the area in hectares and the variation in costs when costs are calculated relative to the production in hectoliters. Regression equations are $y=1.0044 x+0.1954\left(R^{2}=\right.$ $0.8777)$ and $y=0.8926 x+0.2184\left(R^{2}=0.4089\right)$ respectively for grape growing costs and harvest costs 
five vineyards, nearly half of the crop management sequences were redesigned (4R for ME2, ME7, and ME13; $5 R$ for ME12 and 6R for ME10 for nine technical operations), which explains the final $\mathrm{R}$ score.

\subsection{Economic impact of conversion on production costs}

\subsubsection{Production cost analysis}

The conversion period has an impact on the grape growing and harvest costs (Fig. 3). Some winegrowers saw increased per-hectare production costs for grape growing (7/13), while others reduced these costs $(6 / 13)$. The intensity of the variations are highly variable (from $-€ 3460 /$ ha to $+€ 3861 / \mathrm{ha}$ ). Looking at the variation in the per-hectare harvest costs shows the same variations from an increase (7/13) to a decrease (6/13) in costs. However, an increase in the grape growing costs is not clearly linked to an increase in the harvest cost. For example, the grape growing cost increases for ME2 and ME6 while the harvest cost decreases. Harvest costs are always lower than grape growing costs (they make up 2 to $45 \%$ of grape production costs); accordingly, the analysis focuses on grape growing costs to assess the changes. Conversion is not necessarily linked to higher per-hectare costs. Moreover, using per-hectare costs is often not the best way to evaluate economic changes during conversion because yields play a role in cost evaluation. Based on equal per-hectare costs, the final cost of bottled wine will increase if yield has decreased. For nearly all the farms (Fig. 3), there is a similar change between the per-hectare grape growing cost variation and the per-hectoliter cost variation (covariance analysis $p$ value $=$ 0.7398). When per-hectare grape growing costs decrease, the per-hectoliter costs also decrease (three farms: B1, B2, B7). The same change occurs for the six farms that have an increase in their grape production costs (B5, ME1, ME2, ME4, ME5). Only five farms (B3, B4, B6, ME3, ME6) show an opposite variation, with either a yield decrease (B3, B6, ME3) or a yield increase (B4, ME6) during conversion. In fact, yield fell sharply for 2/13 farms during conversion (B3, B6). Grape production costs were nearly double for B6 between the year before the conversion and the first year of certification. For B3, the drop in yield was offset by fewer vine operations. Although the sample is small, it shows that for vine production for the period surveyed, a yield effect is much less visible compared to other changes in how organic grapes are grown.

Finally, according to the percentage of grape growing cost variation, three different cases were observed:

- Most vineyards saw a minor change with a slight variation in costs (overall variation of less than $50 \%$ regardless of the unit—per hectare or per hectoliter): B1, B2, B7 decrease per hectare and per hectoliter costs, whereas
B5, ME2, ME5, B3, B4, B5, B7, ME2, ME3, ME5, ME6 decrease per hectare costs.

- Two vineyards saw a major change in costs (overall variation of more than $50 \%$ regardless of the unit - per hectare or per hectoliter): ME1 and ME4.

- Finally, one vineyard (B6) with a change showing an impact on yield (reduced costs per ha, increased costs per hl)

In the shift towards organic farming, three different strategies could be highlighted among the different farms: the mechanization of technical operations (instead of using chemicals), the de-mechanization of agricultural work (e.g., harvesting at labor-intensive vineyards), and the use of service providers. Of the six vineyards that experienced a significant increase in their costs, three chose to mechanize their farming operations, another opted to increase the share of manual tasks, and one increased the share of external expenses and purchases.

\subsubsection{Linking production costs and technical changes}

Results indicate that managing technical changes when converting can help maintain or even reduce per-hectare costs. This idea is not often emphasized, as many winegrowers believe that converting to organic automatically means increased costs. In fact, the technical process - mostly when yield is limited and not extremely complicated to achieve - can be managed while converting without significant changes in costs. However, in some cases, the yield impact can change (increase) the final costs per hl. The data analysis of the farms surveyed both for agronomic and economic changes shows no links between the type $(\mathrm{E} / \mathrm{S} / \mathrm{R})$ and intensity of the technical changes and the cost variations. These results mean that to fully evaluate the conversion costs, the initial conditions (before the official conversion) of both the biophysical and the technical subsystems must be considered in greater detail. Depending on those conditions, organic conversion may or may not have a deep impact on the systems (as well as on yields or production costs). This drawback could be overcome by characterizing the type $(\mathrm{E} / \mathrm{S} / \mathrm{R})$ and the intensity of the technical changes. However, it appears that these categorizations are not sufficiently relevant to predict economic impacts. For example, $\mathrm{R}$ changes require reorganization and managerial skills that do not necessarily lead to an increase in direct production costs; on the other hand, $\mathrm{S}$ changes may result in new investment that can impair economic performance, but this also depends on what was previously used and will be used (and how) in the future. In vine cultivation, alternative chemical products are available (e.g., copper and sulfur) that can effectively control grape diseases; accordingly, lower yields with organic conversion 
can be avoided. Winegrowers' conversion plans are comprehensive and include the winery, winemaking process, type of wine, and commercialization (Alonso Ugaglia and Del'homme 2012). Organic wine can generally be sold at higher unit prices. This is an opportunity to reduce total vineyard surface, disregarding (temporarily) the "worst" vine plots (for organic production) to support the same level of perhectare production at a farm scale. Later, when the organic project is well established, attention can be shifted to these "bad" plots, such as by planting a grape variety that is less sensitive to adverse conditions (Merot and Wery 2017). This observation emphasizes the fact that organic conversion needs to be studied at a larger scale, taking into account winemaking and selling activities and land use modifications.

\subsection{The efficiency-substitution-redesign framework and vineyard ecologization}

\subsubsection{Number of changes}

A large range in the number of changes during organic conversion was observed (Table 1). The number of changes varied from two to 17 changes per year during the conversion period. For a quarter of the farms surveyed, the changes were limited (fewer than four changes during the 3 years for the nine technical operations studied). For another quarter of the farms studied, the changes were numerous during the 3 years of conversion (more than 14 changes during the 3 years for the nine technical operations studied). For example, for ME19 the changes were numerous because the conventional technical operations were quite different from organic farming standards. Conversion constituted a rupture in the farm trajectory and most of the changes were made during the first 2 years of conversion. This was consistent with the intensity of changes made. For ME1, the conventional technical operations were not all that different from organic farming. Certain technical operations were already carried out in line with organic rules prior to conversion. The numerous changes indicated a continuous process of improvement and innovation. In fact, changes were still being made during the third year of conversion and $\mathrm{R}$ changes were noted on technical operations that were already following organic rules. Half of the farms made between four and 14 changes during conversion, indicating that most of the farms had already begun to update some of
Fig. 4 The values taken for two indicators, speed of change and change intensity, were calculated for the 16 vineyards studied using the efficiency-substitutionredesign framework application (a). Regression equation is $y=$ $0.8521 x-0.0656$ with $R^{2}=$ 0.508 . The three cases of conversion to organic farming were positioned on the adaptive cycle (b) adapted from Biggs et al. (2010) and enriched with Sutherland et al. (2012)

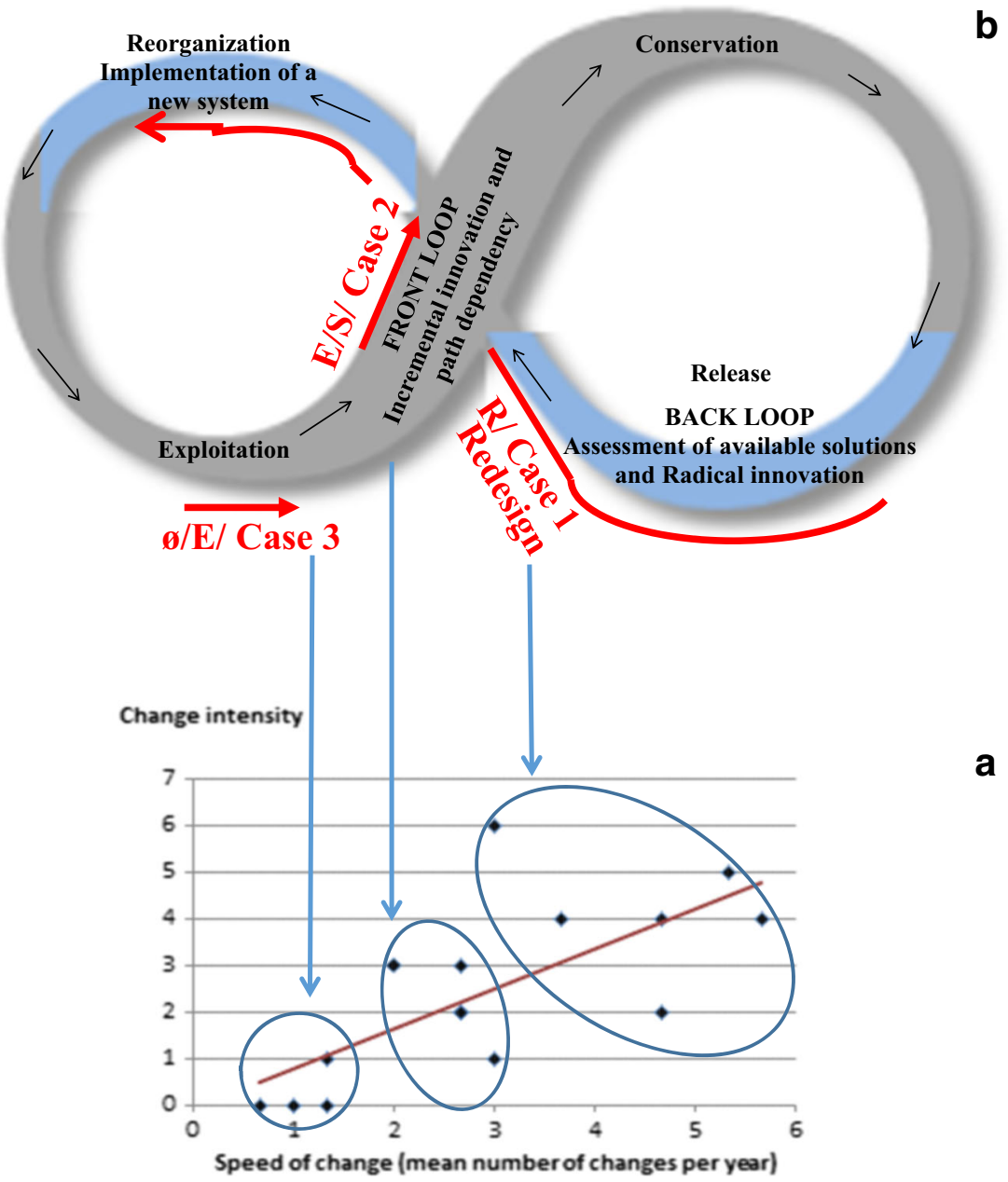


their technical operations to better align with organic farming principles.

\subsubsection{Intensity of changes, speed of change, and resilience}

The number of changes during the 3-year conversion period and the intensity of change characterized by the efficiencysubstitution-redesign framework were analyzed together (Fig. 4a). The intensity of changes ranged from 0 to $6 \mathrm{R}$ and was lower than the number of changes. Fig. 4a shows a trend where the more numerous the changes, the more intense the conversion. For the same number of changes, a variety of situations was noted. For example, among the nine technical operations studied, only one R was identified in one vineyard, and for another vineyard, six $\mathrm{R}$ were identified. This result highlighted the many possible transition conditions. The official conversion process was not placed at the same stage of the vineyard's adaptive cycle (Gunderson and Holling 2002) (Fig. 4b). Three cases were observed: (1) the official conversion is a phase of intense and numerous changes (radical innovation); (2) the official conversion is a phase of mostly E or S changes (incremental innovation); or (3) the official conversion is a calm phase with very few $\mathrm{E}$ and $\mathrm{S}$ changes (exploitation).

As shown in Fig. 4b, the vineyard system's resilience during conversion differed from one case to another. Case 1 is the most intense situation. With regard to the adaptive cycle, conversion began with the release phase to improve connectedness, while the reorganization phase focused on increasing vineyard system resilience. The system underwent rapid change, but converting to organic farming is a good way to preserve system resilience. Moving beyond the back loop (release and reorganization together) required choosing the innovations to introduce and main resources. Case 2 revealed a situation of increased resource competition - mainly laborafter conversion (front loop) whereas case 3 is a no-risk situation because it represents a period of resource expansion.

The efficiency-substitution-redesign framework provided insight into the conversion process and the risks taken by winegrowers. Placing the cases within the adaptive cycle also showed the importance of obtaining knowledge about the initial status before organic conversion. Farm resource availability and the technical operations in particular must be analyzed to determine whether the farm is in the exploitation or the conversion period of the adaptive cycle.

\section{Conclusion}

By using the efficiency-substitution-redesign approach, this study showed that it is possible to classify transition strategies according to a scale of change intensity and speed of changes. This approach was easy to apply to study complex transitions potentially characterized by a significant number of changes such as those observed in vineyard systems. As with many tools, this approach also has its limits. While it provided interesting results for technical change analysis, the approach had to be completed with an analysis of the initial conditions at the beginning of organic conversion. Depending on the initial conditions, a transition to organic may or may not substantially impact the system. This research clearly showed the limits of the efficiency-substitution-redesign approach when assessing economic changes. It highlights the fact that organic conversion must be studied on a larger scale. Taking a vineyard's winemaking and selling activities into consideration seems unavoidable to make official conversion part of the vineyard's business plan and create a more comprehensive process of change that is well represented by the adaptive cycle.

Finally, these results call into question the support winegrowers receive during their transitions. More than ever, winegrowers need tailored advice and assistance when converting to organic farming. The efficiency-substitutionredesign approach could be used to better understand conversion and obtain necessary support.

Acknowledgments We are grateful to all the winegrowers for the time they gave to this study.

Funding The study was funded by the INRA-CIAB research project AgriBio3 P00330.

\section{Compliance with ethical standards}

Conflict of interest The authors declare that they have no conflict of interest.

Publisher's note Springer Nature remains neutral with regard to jurisdictional claims in published maps and institutional affiliations.

\section{References}

Agence bio (2016) L'agriculture biologique - Chiffres clés. Edition 2016 La Documentation Française, Paris

Alonso Ugaglia A, Del'Homme B (2012) Impact économique et financier de la conversion en agriculture biologique $(\mathrm{AB})$ - le cas de la viticulture biologique. Econ Soc 34:2037-2056

Aubert M, Enjolras G (2017) French labour-force participation in organic farming. Hum Syst Manag 36(2):163-172

Bellon S, Penvern S (2014) Organic farming, prototype for sustainable agricultures. Springer, Dordrecht

Biggs R, Westley FR, Carpenter SR (2010) Navigating the back loop: fostering social innovation and transformation in ecosystem management. Ecol Soc 15(2):9

Bouquin H (2004) Le contrôle de gestion, 6th edn. Presses Universitaires de France, Collection Gestion, Paris

Butault JP, Dedryver CA, Gary C, Guichard L, Jacquet F, Meynard JM, Nicot P, Pitrat M, Reau R, Sauphanor B, Savini I, Volay T (2010) Ecophyto R\&D - Quelles voies pour réduire l'usage des pesticides, Synthèse du rapport d'étude. INRA Press, Paris 
De Ponti T, Rijk B, van Ittersum MK (2012) The crop yield gap between organic and conventional agriculture. Agric Syst 108:1-9. https:// doi.org/10.1016/j.agsy.2011.12.004

Estevez B, Domon G, Lucas E (2000) Le modèle ESR (efficacité-substitution-reconceptualisation), un modèle d'analyse pour l'évaluation de l'agriculture durable applicable à l'évaluation de la stratégie phytosanitaire au Québec. courrier environ 41:97-104

European Commission (2018) Farm Accountancy Data Network. EC regulation No 1217/2009. http://ec.europa.eu/agriculture/rica/

Fermaud M, Smits N, Merot A, Roudet J, Thiery D, Wery J, Delbac L (2016) A new multipest damage indicator to assess protection strategies in grapevine cropping systems. Aust J Grape Wine Res 22(3): 450-461. https://doi.org/10.1111/ajgw.12238

Geels FW, Schot J (2007) Typology of sociotechnical transition pathways. Res Policy 36(3):399-417. https://doi.org/10.1016/j.respol. 2007.01.003

Gliessman SR (2007) Agroecology: the ecology of food systems, 2nd edn. CRC Press, Boca Raton

Gliessman SR, Rosemeyer M (2010) The conversion to sustainable agriculture: principles, processes, and practices. CRC Press, Boca Raton

Gunderson LH, Holling CS (2002) Panarchy: understanding transformations in human and natural systems. Island Press, Washington, D.C.

Hill SB, MacRae R (1995) Conceptual frameworks for the transition from conventional to sustainable agriculture. J Sustain Agric 7:81-87. https://doi.org/10.1300/J064v07n01_07

Lamine C (2011) Transition pathways towards a robust ecologization of agriculture and the need for system redesign. Cases from organic farming and IPM. J Rural Stud 27:209-219. https://doi.org/10.1016/ j.jrurstud.2011.02.001

Lamine C, Bellon S (2009) Conversion to organic farming: a multidimensional research object at the crossroads of agricultural and social sciences. A review. Agron Sustain Dev 29(1):97-112. https://doi. org/10.1051/agro:2008007

Le Gal P-Y, Merot A, Moulin CH, Navarrete M, Wery J (2010) A modelling framework to design innovative agricultural production systems. Environ Model Softw 25:258-268. https://doi.org/10.1016/j. envsoft.2008.12.013

Le Pichon V, Filleron E, Ricavy I, Taussig C, Bellon S (2013) Favoriser les innovations agroécologiques par une approche multi-niveaux des besoins d'expérimentation en productions végétales. innov agron 32 : 285-296

Merot A, Wery J (2017) Converting to organic viticulture increases cropping system structure and management complexity. Agron Sustain Dev 37(3):19. https://doi.org/10.1007/s13593-017-0427-9

Pailler J (2004) Ordres de grandeur - Appellations Bordeaux, Bordeaux supérieur 2002. ENITA de Bordeaux, Bordeaux

Patriquin DG (1999) Systems for sustainable agriculture: approaches, tradeoffs and needs. In Sustainable solutions. Dalhousie University, Halifax, pp 95-104

Sautereau N, Petitgenet M (2014) Organic farming: tensions between multiple stakes. Case of organic fruit systems in Provence-AlpesCôte d'Azur Region. rural econ 339-340:145-163. https://doi.org/ 10.4000/economierurale.4276

Seufert V, Ramankutty N, Foley JA (2012) Comparing the yields of organic and conventional agriculture. Nature 485:229-232. https:// doi.org/10.1038/nature11069

Sutherland LA, Burton RJF, Ingrame J, Blackstock K, Slee B, Gotts N (2012) Triggering change: towards a conceptualisation of major change processes in farm decision-making. J Environ Manag 104: 142-151. https://doi.org/10.1016/j.jenvman.2012.03.013

Wezel A, Casagrande M, Celette F, Vian JF, Ferrer A, Peigné J (2014) Agroecological practices for sustainable agriculture. A review. Agron Sustain Dev 34(1):1-20 